\title{
- AMINO-ACIDURIA ACCOMPANYING UNTREATED PERNICIOUS ANAEMIA AND SUBACUTE COMBINED DEGENERATION OF THE SPINAL CORD
}

\author{
BY
}

\author{
C. W. CRANE,* R. A. HAYES, AND G. C. de GRUCHY
}

From the University of Melbourne and Walter and Eliza Hall Institute of Medical Research, Melbourne, the Alfred Hospital, Melbourne, and St. Vincent's Hospital, Melbourne

(RECEIVED FOR PUBLICATION SEPTEMBER 25, 1957)

Weaver and Neill (1954) reported abnormal excretions of taurine, sometimes accompanied by over-excretion of lysine, cystine, and leucine, in the urine of five patients suffering from pernicious anaemia. In one patient with subacute combined degeneration of the spinal cord in whom the blood picture was normal, they found that taurine alone was excreted in abnormal quantities. After treatment with vitamin $B_{12}$ or liver extract, the urinary amino-acid patterns reverted towards normal. They employed the two-dimensional chromatographic method of Datta, Dent, and Harris (1950), using a quantity of urine containing $250 \mu \mathrm{g}$. of nitrogen applied to papers $15 \mathrm{~cm}$. square.

Keeley and Politzer (1956) reported a similar type of amino-aciduria occurring in an African with untreated pernicious anaemia and showed that in 11 cases of megaloblastic anaemia associated with pregnancy and with malnutrition there was no evidence of an abnormal amino-aciduria.

These findings are of considerable interest since urinary chromatography could provide a useful means to differentiate between these anaemias and, as Weaver and Neill suggest, might help in the early diagnosis of subacute combined degeneration of the spinal cord, especially when haematological changes are minimal or absent.

The purpose of this paper is to report the results of the examination for amino-acids by means of chromatography of urine samples from nine cases of untreated pernicious anaemia, two having subacute combined degeneration of the spinal cord.

\section{Clinical Features}

The diagnosis of pernicious anaemia in Cases 1-9 (Table I) was based on the presence of macrocytic anaemia, megaloblastic bone marrow, histamine-fast achlorhydria, and the return of the

\footnotetext{
* Now at Department of Chemical Pathology, St. Mary's Hospital Medical School, London.
}

peripheral blood and bone marrow to normal after $\vec{N}$ adequate vitamin $B_{12}$ therapy. There was no 0 evidence of neurological involvements in seven of these patients. In Case 2 there was evidence of $\vec{z}$ subacute combined degeneration of the cord, 음 whilst Case 9 presented with this condition and $\frac{O}{\partial}$ showed only minimal haematological abnor- $\vec{c}$ malities. This case has been fully reported else- $\subseteq$ where (Robertson, Wood, and Joske, 1955). The age, sex, and haemoglobin values of each patient before treatment are given in Table I.

TABLE' I

AGE AND SEX OF PATIENTS, INITIAL HAEMOGLOBIN VALUES, AND ABNORMAL FEATURES OF URINARY AMINO-ACID PATTERN

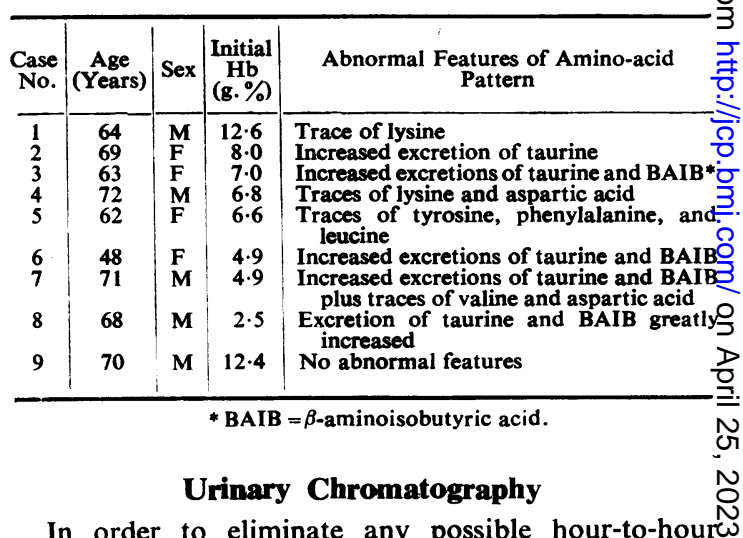

In order to eliminate any possible hour-to-hourw variations in the urinary amino-acid pattern through-? out the day, samples were taken for chromatographyo from 24-hour collections from eight of the patients and stored at $4^{\circ} \mathrm{C}$. under toluene. In Case 8 becauses of the severe anaemia ( $\mathrm{Hb} 2.5 \mathrm{~g}$. \% on admission) $\mathrm{a}_{0}$ 12-hour collection only was possible before treatment5 was begun. Chromatography was repeated in six cases when satisfactory remissions had been produced? with vitamin $B_{12}$ therapy. Volumes of desalted urine containing $250 \mu \mathrm{g}$. nitrogen (micro-Kjeldahl) were applied to Whatman No. 4 papers $60 \mathrm{~cm}$. square 
(Dent, 1951). After running in phenol, followed by a collidine/lutidine mixture, the chromatograms were sprayed with a $0.1 \%$ solution of ninhydrin in butanol and finally examined after 16 hours at room temperature. Duplicate runs were made after oxidation with ammonium molybdate and hydrogen peroxide to detect the presence of cystine and methionine. Unidimensional runs in collidine were examined for the presence of tyrosine and histidine after spraying with Pauly's reagent.

\section{Results}

The amino-acid pattern of the urine from the patient with subacute combined degeneration of the spinal cord and minimal haematological findings (Case 9) was normal and identical before and after treatment. It consisted of glycine as the predominating amino-acid with smaller excretions of taurine, serine, alanine, glutamine, cystine, $\beta$ aminoisobutyric acid (BAIB), and a trace of glutamic acid. Histidine was also present before and after treatment. These amino-acids were also detected in the urinary chromatograms from Cases 1-8 before and Cases $1,4,6,7$, and 8 after treatment, mainly in normal concentrations as assessed by the size and intensity of the resultant ninhydrin spots. The abnormal features of each urinary amino-acid pattern before treatment are set out in Table I. (Specimens of urine from Cases 2, 3, and 5 could not be obtained after treatment.)

Slightly increased outputs of several amino-acids appearing as traces on the chromatograms from Cases 1, 4, and 7 were no longer detectable after treatment. Excretions of taurine and BAIB, large initially in Cases 6,7 , and 8 , returned to normal after treatment, and in each of the resultant chromatograms glycine became the predominating amino-acid.

\section{Discussion}

No characteristic urinary amino-acid patterns, common to each case of untreated pernicious anaemia with or without evidence of subacute combined degeneration of the spinal cord, were observed in this series. Of the patients presenting with haemoglobin values of $8 \mathrm{~g} . \%$ or less, two showed minimal and dissimilar departures from the normal pattern (Cases 4 and 5), four increased outputs of taurine and BAIB (Cases 3, 6, 7, and 8), while Case 2 showed excessive taurine excretion alone. With such a lack of uniformity of pattern accompanying this degree of anaemia it seems very unlikely that urinary chromatography will aid in the diagnosis of those cases of pernicious anaemia presenting with minimal haematological abnormalities or equivocal neurological signs. The slightly increased excretions of lysine, aspartic acid, tyrosine, phenylalanine, leucine, and valine which resulted in small or faint spots on the chromatograms in Cases 1, 4, 5, and 7 initially and do not appear in the urinary patterns from normal persons when this technique is used (Dent, 1954 ; Walshe, 1953) could be attributed to mild hepatic dysfunction resulting from fatty infiltration which may accompany pernicious anaemia. An increased excretion of taurine in five out of seven patients with initial haemoglobins of $8 \mathrm{~g}$. \% or less confirms the observations of Weaver and Neill (1954), but at the same time it was not possible to detect excessive outputs of leucine, lysine, or cystine. Four of these patients in addition excreted large quantities of BAIB. Taurine or BAIB may be the predominating amino-acid excreted by normal persons (Dent, 1954 ; Walshe, 1953) and these two substances may occur together in abnormal quantities in the urine of patients suffering from acute or chronic liver disease (Walshe, 1953). It is unlikely that the marked increased excretion of these two substances in our cases was due primarily to liver damage, since excessive quantities of other amino-acids, especially cystine, were absent. Since vitamin $B_{12}$ is concerned in methyl group synthesis and in transmethylation of homocysteine (Jukes, Stokstad, and Broquist, 1950), a lowered rate of synthesis of methionine due to vitamin $B_{12}$ deficiency could result in an enhanced urinary excretion of taurine by degradation of accumulated homocysteine within the body, and it is of significance that in three patients after treatment with vitamin $B_{12}$ the urinary excretion of this substance became normal. A similar situation in respect of thymine and nucleic acid synthesis (Glazer, Mueller, Jarrold, Sakurai, Will, and Vilter, 1954) could account for the enhanced excretion of BAIB, since likewise the urinary excretion of this substance returned to normal after treatment in the cases studied, but there is an alternative explanation. Sandler and Pare (1954) observed that urinary excretion of BAIB was increased early in experimental starvation of young volunteers, and the anorexia and general malaise accompanying severe pernicious anaemia predispose to a similar situation.

It is difficult to assess with confidence any but gross differences in concentrations of urinary amino-acids by means of two-dimensional paper chromatography, and, apart from laborious procedures involving ion exchange, there exists at present no reliable means of estimating BAIB in the urine. Recently Ling (1957) has introduced a method for estimating urinary taurine and it would 
thus be possible to gain more precise data on the excretion of this substance in pernicious anaemia before and after treatment.

One of us (C. W. C.) wishes to thank the Nuffield Foundation for a grant.

\section{REFERENCES}

Datta, S. P., Dent, C. E., and Harris, H. (1950). Science, 112, 621. Dent, C. E. (1951). In Recent Advances in Clinical Pathology, 2nd ed., ed. S. C. Dyke, p. 238. Churchill, London.
Dent, C. E. (1954). Lectures on the Scientific Basis of Medicine, 1952-53, vol. 2, p. 243.

Glazer, H. S., Mueller, J. F., Jarrold, T., Sakurai, K., Will, J. J., and Vilter, R. W. (1954). J. Lab. clin. Med., 43, 905.

Jukes, T. H., Stokstad, E. L. R., and Broquist, H. P. (1950). Arch. Biochem., $25,453$.

Keeley, K. J., and Politzer, W. M. (1956). J. clin. Path., 9, 142.

Ling, N. R. (1957). Ibid., 10, 100.

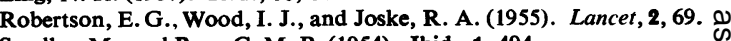

Sandler, M., and Pare, C. M. B. (1954). Ibid., 1, 494.

Weaver, J. A., and Neill, D. W. (1954). Ibid., 1, 1212.

Walshe, J. M. (1953). Quart. J. Med.. n.s., 22, 483. 